\title{
ISOTRETINOIN-INDUCED SKELETAL DISORDERS: A CASE REPORT
}

\section{Camila da Silva Cendon Duran ${ }^{1, \star}$, Nicolas Yamada Tanigava ${ }^{1}$, Luciana Parente Costa Seguro ${ }^{1}$, Rosa Maria Rodrigues Pereira ${ }^{1}$}

1.Universidade de São Paulo, São Paulo (SP), Brazil.

*Corresponding author: milla_duran@hotmail.com

\section{BACKGROUND}

Isotretinoin is an oral synthetic vitamin A derivative especially used in patients with keratinization disorders. Skeletal disorders have been described in patients treated with this drug such as hyperostosis of the cervical and thoracic spine, ossification of the anterior longitudinal ligament and enthesopathy.

\section{CASE REPORT}

Female, 37 years old, with a 3-year history of reduction in cervical range of motion with mild noninflammatory pain. She denied peripheral arthralgia and pain in thoracic and lumbar spine. The patient has a diagnosis of congenital ichthyosiform erythroderma and has been using isotretinoin $0.45 \mathrm{mg} / \mathrm{kg} /$ day for 13 years. The patient had no other comorbidities or symptoms suggestive of inflammatory bowel disease and gastrointestinal/genitourinary infection. Also, no personal or familiar history of psoriasis. Physical examination revealed erythematous and scaly skin lesions and a significant reduction in cervical mobility. Other spinal movements were intact and painless and peripheral synovitis was absent. Blood tests revealed low vitamin-D level (12 ng/mL); PTH $47 \mathrm{pg} / \mathrm{mL}$ (RV: 15-65), phosphorus 3.8 mg/dL (RV: 2.7-4.5) and calcium 10.3 (RV: 8.4-10.2). The HLA-B27 was negative; C-reactive protein (CRP) and erythrocyte sedimentation rate (ESR) were normal. Radiographs showed cervical, thoracic and lumbar syndesmophytes, calcification of the anterior and lateral thoracic vertebral ligament (Figure 1), enthesopathy of bilateral patellar tendon, bilateral calcaneus, femoral trochanter and ischial tuberosity (Figure 2). Symmetrical bilateral sacroiliitis was also evidenced. Magnetic resonance imaging (MRI) of the sacroiliac joint did not show an inflammatory process. In view of the clinical, laboratory and radiological features, we suggest the possibility of isotretinoin-induced hyperostosis, due to the long-term use of this drug, the lack evidence of inflammatory disease, absence of hyperparathyroidism and low probability of DISH due to the aggressive progression, young age, female gender and absence of comorbidities commonly seen in DISH.
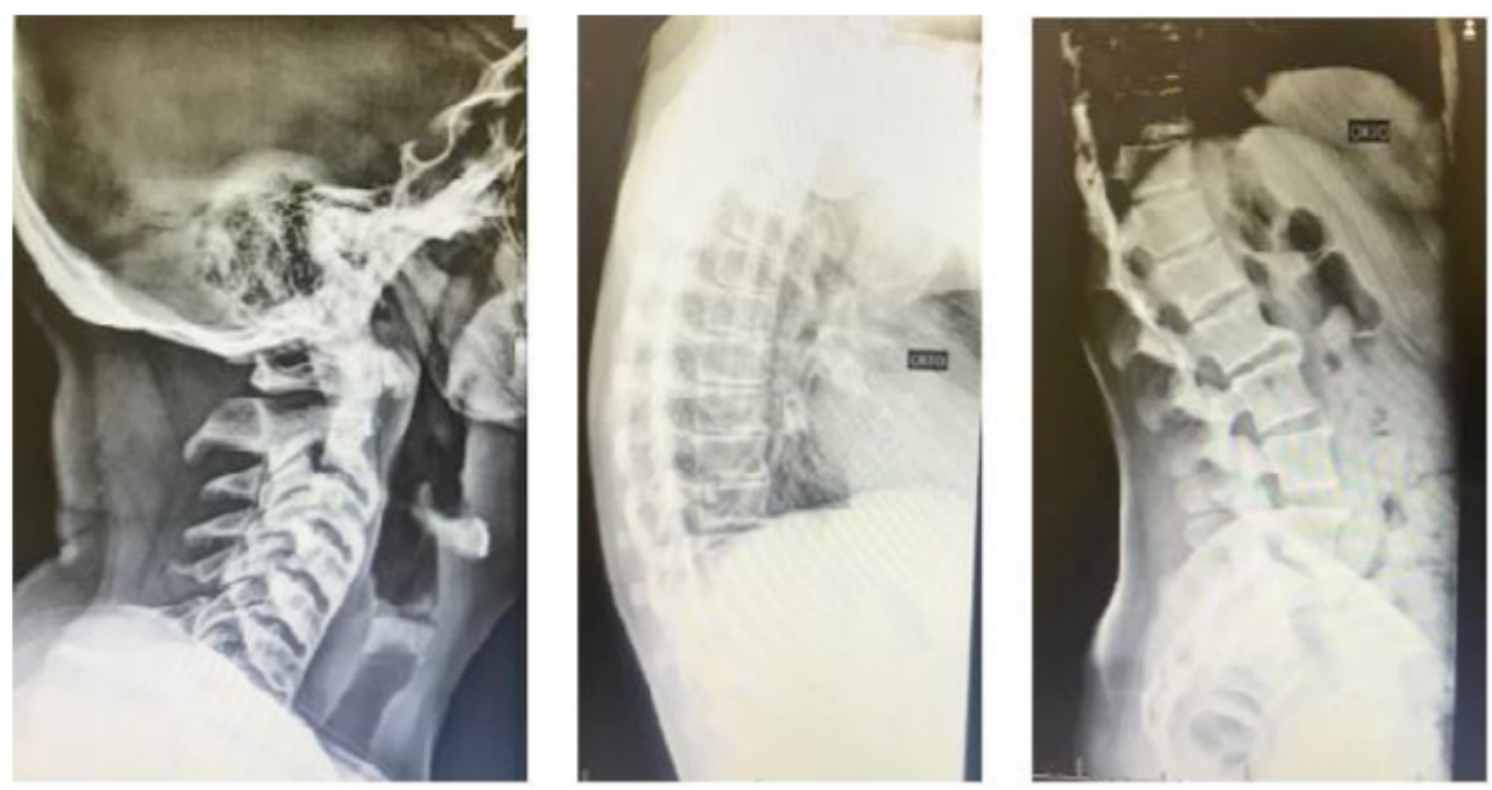

Figure 1. Cervical, thoracic and lumbar syndesmophytes.

Realização: 

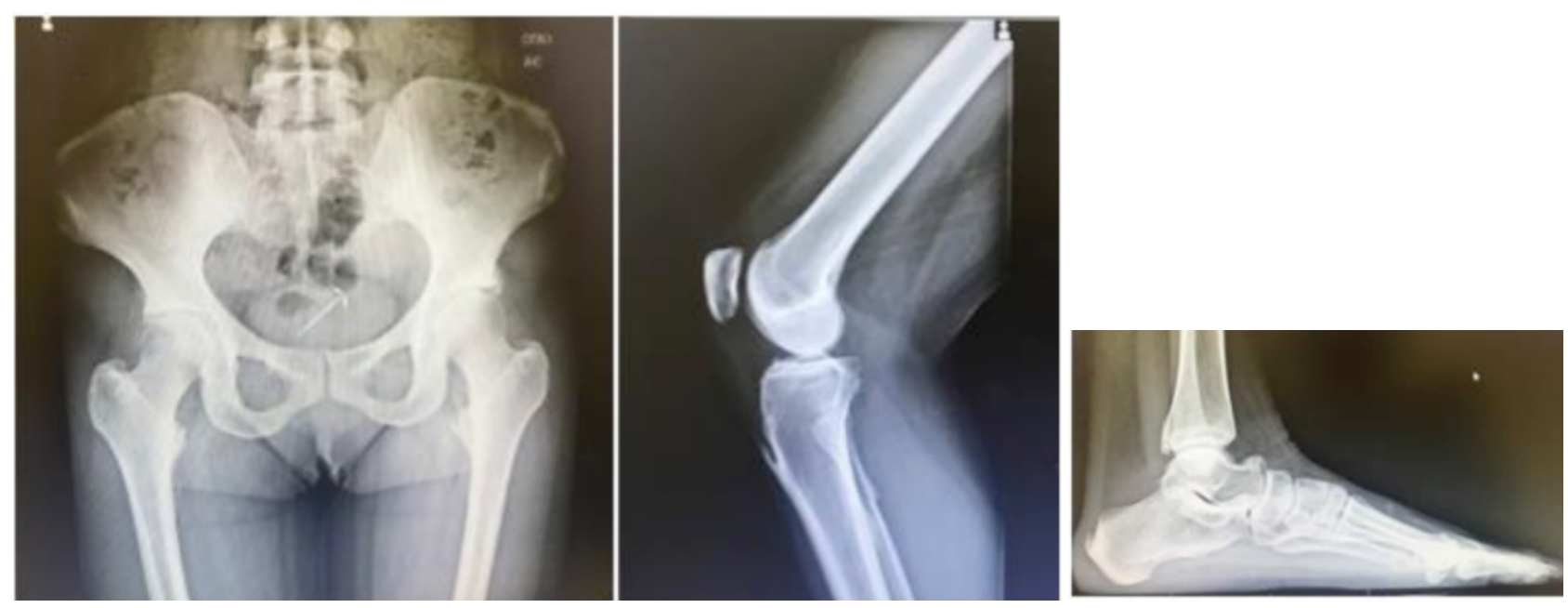

Figure 2. Enthesopathy in patellar tendon, calcaneus, femoral trochanter and ischial tuberosity.

\section{CONCLUSION}

Rheumatologic disorders such as unilateral or bilateral sacroiliitis, peripheral arthritis, enthesopathy and spinal hyperostosis have been described in patients using isotretinoin. The pathophysiological mechanism is poorly understood but high doses and continuous long-term use of the drug seem to be associated with a higher risk of developing these conditions.

\section{KEYWORDS}

Isotretinoin, Hyperostosis, Enthesopathy. 